\title{
THE EFFECT OF SECTION OF THE POSTERIOR CILIARY ARTERIES IN THE RABBIT
}

\author{
BY \\ JOHN V. V. Nicholls* \\ (FROM THE DEPARTMENT OF PHYSIOLOGY, \\ UNIVERSITY COLLEGE, LONDON)
}

\section{Introduction}

Over 45 years have passed since Wagenmann (1890) carried out his classical experiments on rabbits, in which he produced a pigmented degeneration of the retina by section of the posterior ciliary arteries. His observations were repeated and confirmed by Krückmann (1899) on rabbits, and by Capauner (1893) on frogs and rabbits. Nevertheless, it seemed that it might be advisable to repeat his experiments and re-evaluate his results in the light of present day knowledge, and especially so because of the controversy that has existed for many years on the question of the pathogenesis of retinitis pigmentosa. Gonin (1902), Nettleship (1903), Greeves (1912) and others, have all suggested that a choroidal vascular disturbance must be the underlying cause and Wagenmann's experiments have figured largely in the arguments which have been advanced in favour of this view. In 1919 Treacher Collins put forward another theory. He suggested that there was some inherent weakness of the rods and cones that caused them to die. He adopted the term "abiotrophy" to describe his idea of the underlying process. The vascular theory has also been opposed by Verhoeff (1931). Lately further evidence supporting Collins' idea has emerged from the work of Bourne, Campbell and Tansley (1938) on familial degeneration of the retina in rats. The findings of these latter workers indicate that there is no choroidal vascular lesion.

In the present experiments the technique described by Wagenmann was followed as closely as possible. In this, certain difficulties arose that make it necessary to qualify certain of Wagenmann's statements. Preliminary anatomical studies of the distribution of the posterior ciliary arteries in rabbits showed their close relationship with the ciliary nerves. The arteries and nerves are so intimately entangled, corkscrewing about each other, that it is impossible to cut, tear or twist the arteries without injuring the nerves. Wagenmann also stated that interference with only a few posterior ciliary arteries was enough to produce retinal degeneration in the area supplied. The results of the

\footnotetext{
* Travers Allen Travelling Fellow.
} 
present series of experiments indicate that a much greater interference is necessary.

\section{Methods}

Young adult rabbits were used, which were for the most part pigmented. Nembutal was the anaesthetic employed with the occasional addition of a little ether. The nembutal was given intraperitoneally in doses of 5 grams per kilo. of body weight.

The retrobulbar structures were exposed by section of the superior rectus muscle at its insertion and by rotation of the eye downwards. A poorer, though adequate, exposure can be obtained by section of the inferior rectus muscle and rotation of the eye upwards. This is so because the optic nerve enters the globe somewhat above its posterior geometric centre. In these experiments the approach from above was used most frequently. The ciliary arteries and nerves enter the eye about the optic nerve, but their main bulk lies slightly below and to each side of it. Some difficulty was encountered from the hæmorrhage occurring immediately on cutting the arteries, which tended to obliterate all fine structures. This difficulty was largely overcome by carefully localising all structures before cutting the arteries. The inferior or superior rectus muscle, as the case might be, was then sutured in place and the conjunctival wound was closed. By preserving aseptic surgical technique throughout, the wound rapidly healed with no untoward effects.

Altogether twenty eyes were operated upon. They were removed at intervals of $3,4,7,10,17,30$ and 126 days after operation. This was carried out under anæsthesia and the eyes were immediately placed in Zenker's solution. After dehydration and clearing they were embedded in paraffin. Sections were cut $8 \mu$ thick. Haematoxylin and eosin were used generally for staining, but both Feulgen's nuclear stain and Mallory's phosphotungstic acid haematoxylin stain were used to show finer details.

Actual counts were made of the number of rods and cones in the degenerated areas and in the corresponding normal areas in an attempt to determine their relative rates of degeneration.

\section{Results}

One of three results occurred after section of the posterior ciliary arteries, depending on the number of vessels cut. There might be no changes, complete phthisis bulbi, or a localised area of retinal degeneration in the region supplied by the bulk of the vessels sectioned. In order to produce an area of degeneration it was found necessary to interfere with at least two thirds of all the posterior ciliary arteries. Even then the results were uncertain. 
Nothing at all might occur or there might be phthisis bulbi. It seemed that the collateral circulation of the choroid was so good, that it was very difficult to interfere with just enough vessels and not too many. These results do not confirm the statement of Wagenmann that section of only a few ciliary arteries was necessary. They are in keeping, however, with the present day knowledge of the vast and ramifying interconnections of the choroidal vessels. Subject to these qualifications the present findings support those of Wagenmann.

Of the three possible results of section of the posterior ciliary arteries those cases where there were areas of local degeneration of the retina mainly concern us. In these cases the first change to be noticed ophthalmoscopically was an area of extreme pallor coming on immediately after operation. The retinal vessels always appeared normal in calibre. The pale area spread roughly fanwise from the optic nerve head out to the ora serrata. Within a very few hours this area became somewhat less pale and definitely swollen with less sharply outlined edges, indicating an oedematous process. In about a week this picture gradually changed. As the circulation was restored in certain areas the normal appearance returned. In others where the circulation was

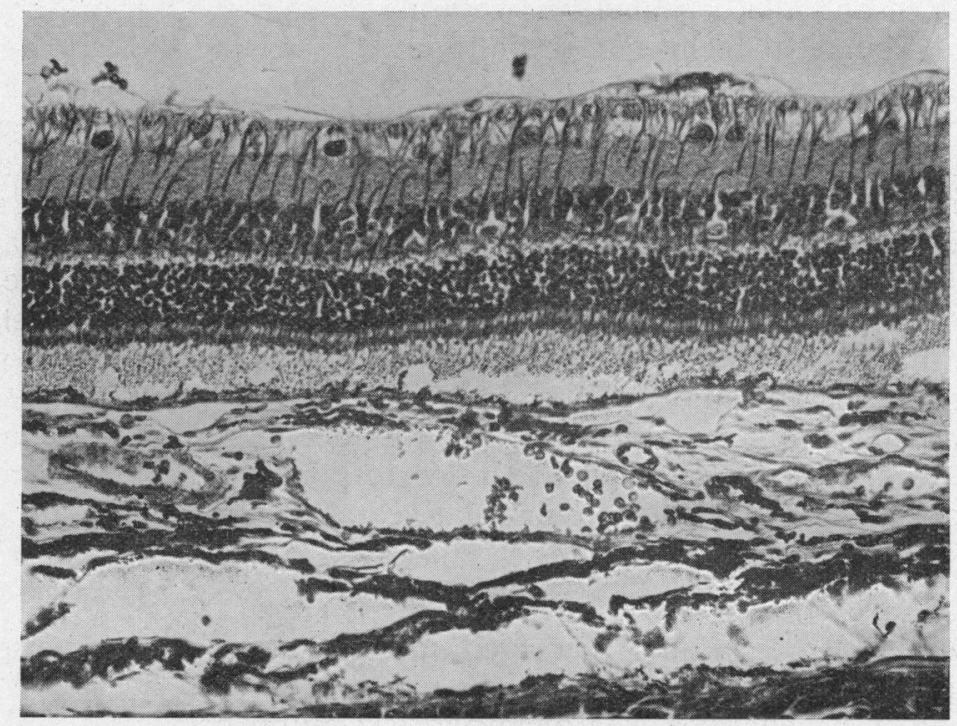

Fig. 1.

Section which shows the normal retina and choroid in a moderately pigmented rabbit. Zenker: Haematoxylin and Eosin. $\times 10$. 


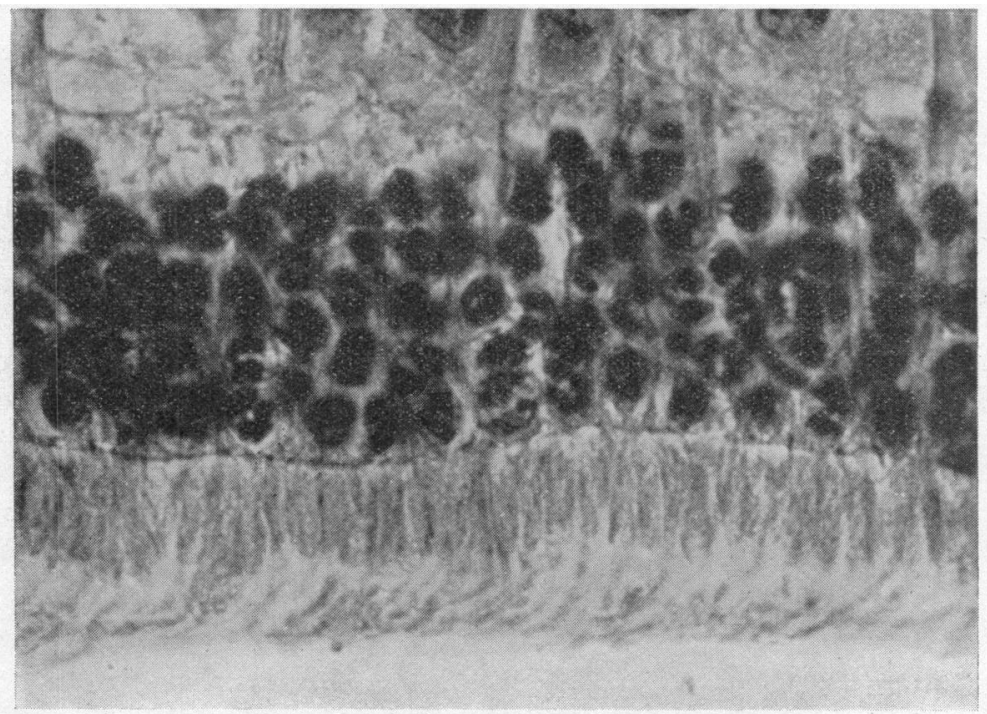

FIG. 2.

Section which shows the details of the outer nuclear, and the rod and cone layers in a normal rabbit retina. Note the cone nucleus in the centre of the field lying upon the external limiting membrane. Zenker: Haematoxylin and Eosin. $\times 940$.

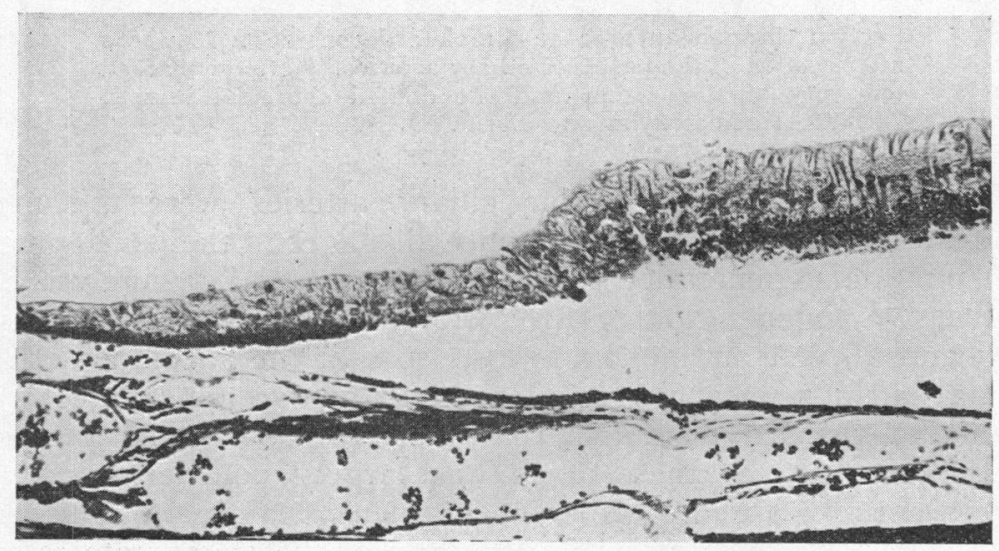

FIG. 3.

Section through the border of an area of retinal degeneration 17 days after section of the posterior ciliary arteries. Note the marked degeneration starting with the outer nuclear and rod and cone layers, and the dilated choroidal vessels. Zenker: Haematoxylin and Eosin. $\times 110$. 
not restored the retina remained pale and gradually became spotted here and there with round sharply circumscribed dense accumulations of pigment. These latter areas were seen to be grouped for the most part in the region of the equator. At no time or place was the pigment seen to have any relation to the retinal vessels. The changes progressed over several weeks and reached a stabilised state in about four or five months. Contraction of the degenerated areas finally took place and threw the normal areas into shallow folds.

The histological changes in the retina were in exact agreement with the ophthalmoscopic findings. The changes seen two weeks

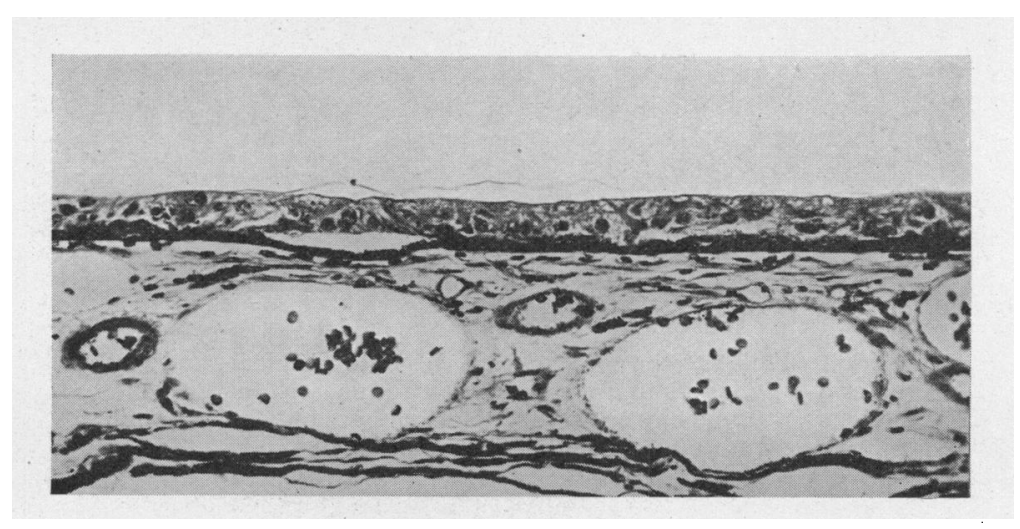

FIG. 4.

Section through an area of complete degeneration 19 weeks after section of the posterior ciliary arteries. Note the marked tenuosity of the retina and the dilated choroidal vessels. Zenker: Haematoxylin and Eosin. $\times 210$.

after section of the posterior ciliary arteries were the most interesting since they showed at once all stages in the development of the retinal degeneration (Fig. 3). The essential change was one of massive degeneration of all layers of the retina. This became thin and all cell outlines were lost, so that the substance of the retina had a somewhat homogeneous granular appearance with here and there a degenerate nucleus (Fig. 4). The pigment epithelium beneath these areas was largely degenerate and in places entirely absent, while the pigment, mainly in rod form, tended to migrate into the deeper parts of the degenerate retina, where for the most part it was contained in large round cells. Considerable quantities, however, could be seen free and in clumps. At the borders of the areas of complete degeneration the retina showed gradual thinning of the rods and cones and outer nuclear layers, and, in places, oedema of the outer reticular 
layer. The signs of degeneration of the rods and cones were first crumpling and fragmentation of the outer limbs, secondly of the inner limbs, and finally, the nuclei became pyknotic. In general the nuclei showed an extraordinary resistance to the degenerative process (Fig. 5). The pigment epithelium beneath these border areas showed little or no change unless the external limiting

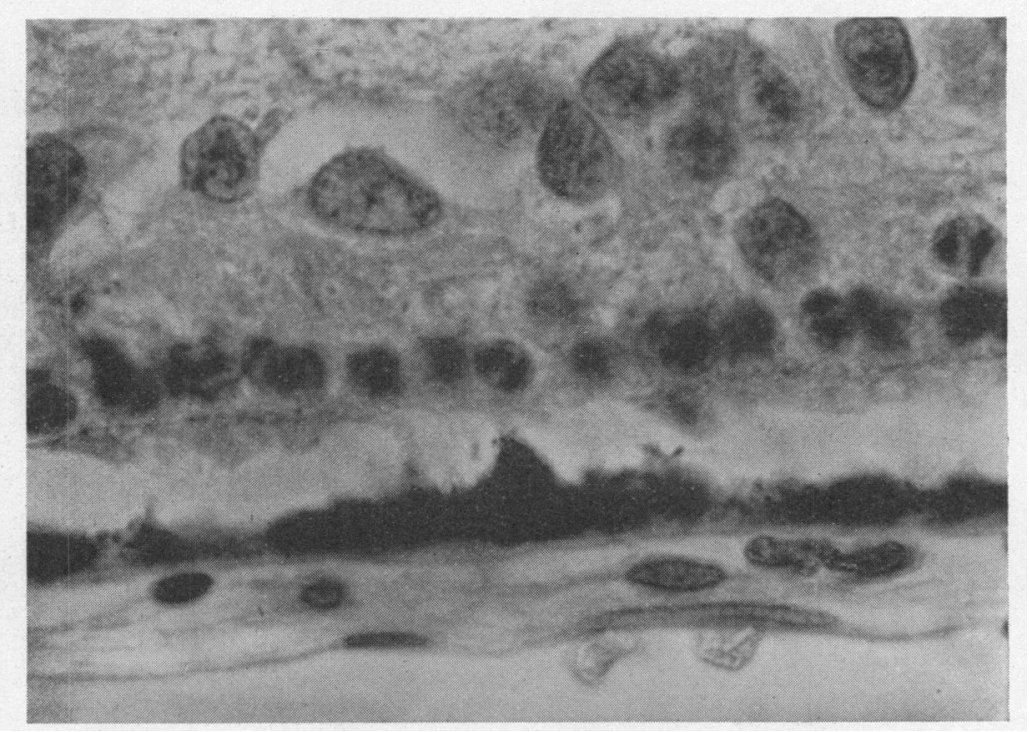

FIG. 5.

Section through the border of an area of degeneration 17 days after section of the posterior ciliary arteries, which shows the very thin outer nuclear layer and the much degenerated rod and cone layer. In spite of this the rod nuclei present are well preserved. Note the degeneration of the pigment epithelial layer in the centre of the field. Just above this the external limiting membrane is defective. Here the pigment has begun to migrate. Zenker: Haematoxylin and Eosin. $\times 940$.

membrane was involved, when migration of pigment took place and the pigment epithelium became attached to the retina rather than to the choroid (Fig. 6). This is in agreement with the findings of Treacher Collins, who believed that the pigment migrated through gaps in the external limiting membrane left by the degenerated rods and cones. Where there was marked destruction of the outer nuclear and the rod and cone layers, glial and fibrous tissue replaced the loss. Also scattered polymorphonuclear leucocytes could be seen in these areas (Fig. 7).

The process is thus seen to be a pigmented degeneration of the 
retina starting in the deeper layers and finally spreading throughout the retina. The histological changes in an eye removed five months after section of the posterior ciliary arteries supported this view. By this time the process had become stabilised. Normal retina abutted more sharply on areas of complete

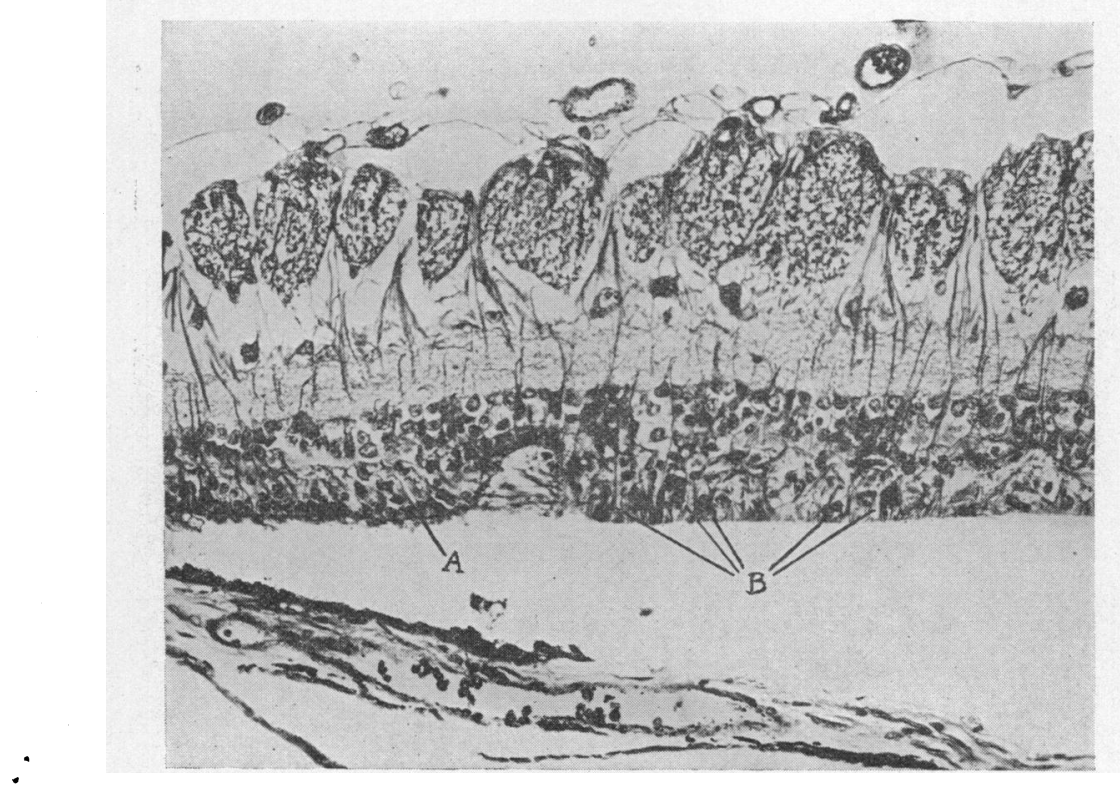

FIG. 6.

Section through the border of an area of retinal degeneration in a rabbit 17 days after section of the posterior ciliary arteries which shows the migration of pigment. On the surface of the retina can be seen bundles of myelinated nerve fibres, which in the rabbit extend horizontally on each side of the optic nerve bead.

A. External limiting membrane.

B. Pigment in clumps.

Note that the pigment epithelium is degenerate and the pigment has migrated only where the external limiting membrane has disappeared. Zenker: Haematoxylin and Eosin. $\times 210$.

degeneration. In the latter the retina was remarkably thin, showing a mixture of ill-defined cell remnants and glial tissue. In the deeper parts there were numerous large round cells stuffed with pigment, which tended to group together. Where this grouping took place there was also much extracellular pigment, free and in clumps. This accounts for the ophthalmoscopic picture seen at this stage. The pigment epithelium beneath these areas was degenerate and irregularly swollen and in some places 
absent. On the borders of these regions, there was a rapid thinning of the outer nuclear layer, while little organisation, and no oedema of the outer reticular layer could be seen. Close to the area of complete degeneration the outer reticular layer was frequently found to be collapsed, so that the remaining nuclei of

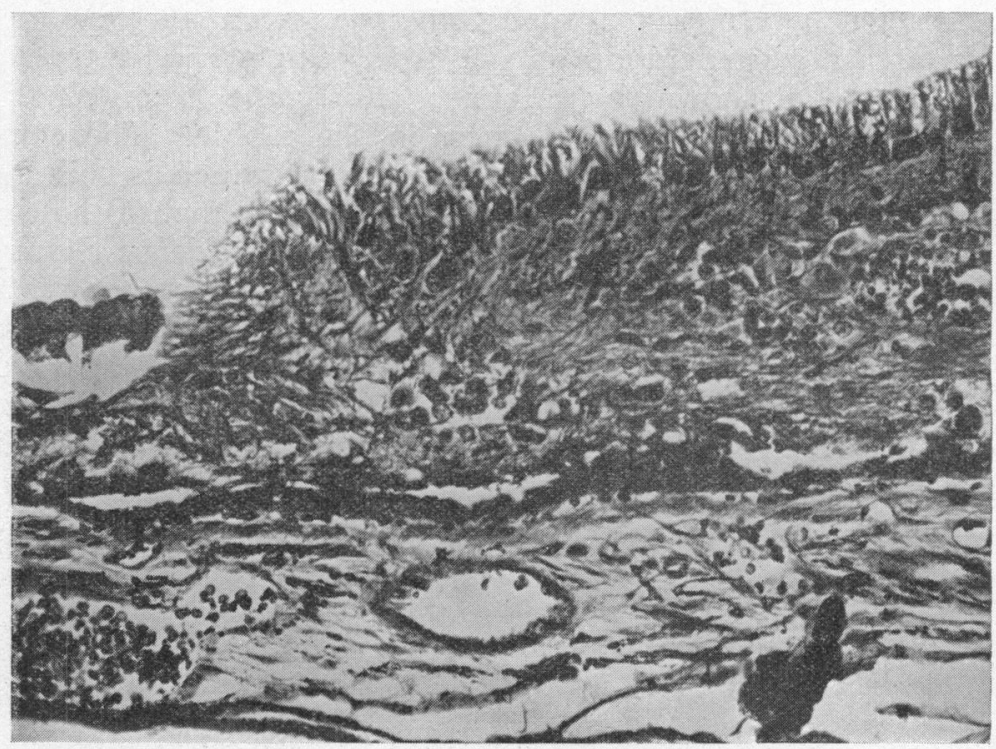

FiG. 7.

Section through the border of an area of retinal degeneration 17 days after section of the posterior ciliary arteries, which shows glial tissue replacing the loss of tissue. Note the group of polymorphonuclear leucocytes in the retina at the extreme right. Zenker: Haematoxylin and Eosin. $\times 210$.

the outer nuclear layer and those of the inner nuclear layer intermingled.

The changes in the choroid were interesting but not very marked. The sections showed that the vessels were dilated and contained a good deal of blood, indicating a stagnation of blood rather than an hyperaemia. Here and there the choroid was thinner than normal, the vessels being smaller and empty. The existence of either picture seemed to bear little uniform relationship to the degree of retinal degeneration. Even under normal conditions there are great variations in the vascularity of different parts of the same choroid. It would seem that the choroid is normally under a continually varying neuro-vascular control and 
that after an operation of this nature the process was apparently exaggerated.

Actual counts were made of the rods and cones to determine if possible the relative rates of their degeneration. The counts were made on an eye removed nineteen weeks after section of the posterior ciliary arteries. This stage of degeneration was chosen because the picture had become stabilised at that time. A section was selected which ran through the centre of the eye and had an area of degeneration on one side, with normal retina on the other. As shown by Menner (1929) the rods can be distinguished easily from the cones, in the rabbit. The cones have an egg-shaped nucleus, the chromatin of which is collected in a network of threads. It is slightly larger than that of the rod, the chromatin of which is collected in two or three dense clumps, separated by a clear non-staining area (Fig. 2). The cone nuclei are situated near or right above the external limiting membrane while the rod nuclei are situated farther away and arranged roughly in columns. Menner remarks on the difficulty of distinguishing between the processes of the rods and cones in the rabbit. The present author found that the outer limb of the cone tends to be a little shorter than that of the rod, while the inner

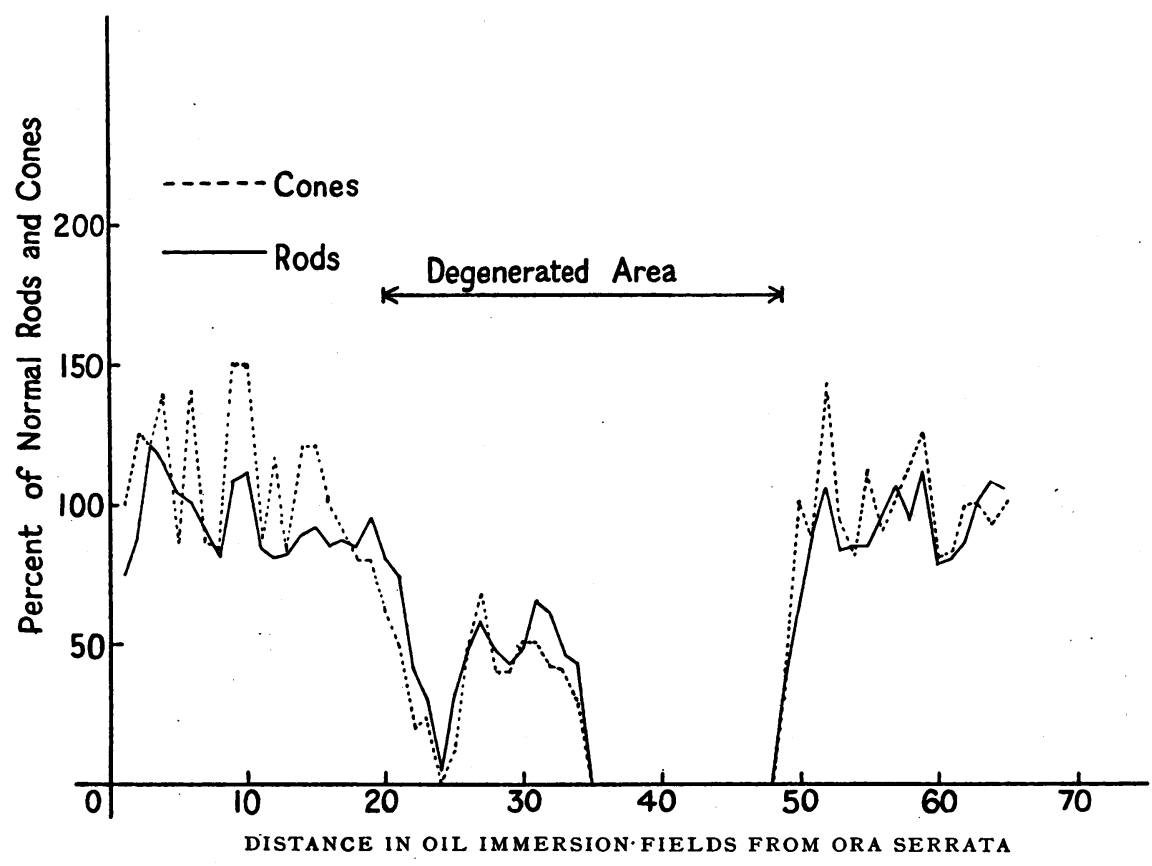

FIG. 8. 
limb is slightly broader particularly at its upper end, in which the nucleus is situated. The differences were so slight, however, that the two could most easily be distinguished by the difference in their nuclei.

As the degeneration produced by interference with the posterior ciliary arteries affected the nuclei last of all, quite accurate comparisons could be made by counting the number of rod and cone nuclei that could be distinguished as such in each oil immersion field. As only the relative number of rods and cones in any one particular area was of interest, slight variations in the thickness of the section could be ignored. In Table I the rod and cone counts have been tabulated, the counts on the degenerated side being placed alongside those of the corresponding area on the normal side. Each count has been numbered in the table as so many oil immersion fields from the ora serrata. The diameter of one oil immersion field was calibrated and found to measure $0.175 \mathrm{~mm}$. The ora serrata in the rabbit is $2.0 \mathrm{~mm}$. from the limbus, so by means of simple calculation the exact topographical location of each count can be determined. In Figure 8 the results have been presented in another way; the percentage change in the rod and cone counts on the degenerated side have been plotted against the distance in oil immersion fields from the ora serrata, taking the respective counts on the normal side as 100 per cent. The graph shows that the rods and cones degenerate equally rapidly. These results were checked and confirmed by other and less exhaustive counts on different eyes.

\section{Discussion}

The histological changes described by Wagenmann are exactly similar to those found in the present experiments. That they are the result of a purely vascular disturbance must, however, be accepted with some reservations, which though probably unimportant are none the less real. As stated above it is impossible to interfere with the posterior ciliary arteries without injuring the ciliary nerves, because of their intimate anatomical relations to one another. In evaluating the results of such a procedure one must keep in mind the possible trophic or neurovascular functions of these nerves. In point of fact the possibility of neuro-vascular functions need not cause us concern as the whole purpose of this form of operation is to produce a vascular lesion. But the possibility of pure trophic functions must be kept in mind. In this connection, however, it should be remembered that not only is there no evidence that the ciliary nerves have any pure trophic functions, but that there is much negative evidence 
indicating that no such functions exist. In the present series of experiments the first signs of degeneration were seen in the cytoplasm of the rods and cones, while pure trophic disturbances are usually indicated by a degeneration appearing first in the cell nucleus. In serial sections through eyes in which only a few posterior ciliary arteries, and of course, ciliary nerves, had been cut, not the slightest evidence of retinal degeneration was ever found. If the ciliary nerves had any pure trophic functions, there should be some evidence of it in such sections. Further, Capauner's results on frogs, in which he cut the ophthalmic artery, presumably without injuring the ciliary nerves, indicates that Wagenmann's and the present results can be accounted for by a purely vascular disturbance.

In applying the results of these experiments to man, and in using them as contributory evidence in favour of the vascular theory of retinitis pigmentosa further reservations must be made. There is an important difference between the choroidal circulation in the rabbit and that in man. In the former the posterior ciliary arteries are functional end arteries and have no intimate connection with the anterior ciliary arteries as is the case in man (Studer 1906). This accounts for the fact that the areas of degeneration occur in the region of the equator, that is, immediately over the terminal arborization of the posterior ciliary arteries. In man they probably would have no such localisation. Studer's (1906) case, in which the posterior ciliary arteries, some of the anterior ciliaries and the optic nerve were cut in a patient with a painful glaucomatous eye, indicates that in man some of the anterior ciliaries must be cut also in order to produce retinal degeneration. In this case the area of degeneration extended right up to the ora serrata, and was confined to the side on which the anterior ciliary arteries had been cut, as a result of section of the external rectus muscle made in order to procure a good exposure. In the present series of experiments the area of degeneration bore no such relation to the muscle cut. If then at least two-thirds of all the posterior ciliary arteries must be cut to produce an area of retinal degeneration in the rabbit, it is apparent that a great many more would have to be cut in man, where the collateral circulation is better, in order to produce a similar lesion. Such vascular abnormalities as have been described in the choroid in cases of retinitis pigmentosa would not have an effect even vaguely approaching such changes.

Mention must be made also of the ophthalmoscopic changes produced by section of the posterior ciliary arteries. At no time or place do they ever have the least similarity to those found in retinitis pigmentosa. 
Ciliary ARteries in the Rabít

TABLE I

\begin{tabular}{|c|c|c|c|c|c|c|}
\hline \multirow{2}{*}{$\begin{array}{l}\text { Distance } \\
\text { FROM } \\
\text { ORA } \\
\text { SERRATA }\end{array}$} & \multicolumn{2}{|c|}{$\begin{array}{c}\text { TEM PORAL SIDE } \\
\text { (degenerated) }\end{array}$} & \multicolumn{2}{|c|}{$\begin{array}{l}\text { PER CENT. OF } \\
\text { NORMAL }\end{array}$} & \multicolumn{2}{|c|}{$\begin{array}{l}\text { NASAL SIDE } \\
\text { (normal) }\end{array}$} \\
\hline & Rods & Cones & Rods & Cones & Rods & Cones \\
\hline 1 & 60 & 4 & 75 & 100 & 80 & 4 \\
\hline 2 & 80 & 5 & 89 & 125 & 90 & 4 \\
\hline 3 & 126 & 6 & 121 & 120 & 104 & 5 \\
\hline 4 & 120 & 7 & 114 & 140 & 105 & 5 \\
\hline 5 & 125 & 6 & 104 & 86 & 120 & 7 \\
\hline 6 & 120 & 7 & 100 & 140 & 120 & 5 \\
\hline 7 & 110 & 6 & 91 & 86 & 120 & 7 \\
\hline 8 & 112 & 5 & 81 & 83 & 138 & 6 \\
\hline 9 & 140 & 9 & 108 & 150 & 130 & 6 \\
\hline 10 & 154 & 9 & 112 & 150 & 138 & 6 \\
\hline 11 & 121 & 7 & 84 & 88 & 143 & 8 \\
\hline 12 & 118 & 7 & 81 & 117 & 145 & 6 \\
\hline 13 & 115 & 5 & 82 & 83 & 140 & 6 \\
\hline 14 & 126 & 6 & 89 & 120 & 142 & 5 \\
\hline 15 & 126 & 6 & 93 & 120 & 135 & 5 \\
\hline 16 & 115 & 7 & 85 & 100 & 135 & 7 \\
\hline 17 & 110 & 5 & 87 & 83 & 126 & 6 \\
\hline 18 & 115 & 6 & 85 & 75 & 136 & 8 \\
\hline 19 & 129 & 6 & 95 & 75 & 136 & 8 \\
\hline 20 & 120 & 5 & 80 & 63 & 150 & 8 \\
\hline 21 & 100 & 4 & 74 & 50 & 135 & 8 \\
\hline 22 & 53 & 2 & 41 & 25 & 128 & 8 \\
\hline 23 & 48 & 2 & 35 & 29 & 136 & 7 \\
\hline 24 & 12 & 0 & 9 & 0 & 135 & 5 \\
\hline 25 & 52 & 1 & 36 & 17 & 143 & 6 \\
\hline 26 & 68 & 2 & 48 & 50 & 143 & 4 \\
\hline 27 & 78 & 2 & 58 & 67 & 135 & 3 \\
\hline 28 & 67 & 2 & 48 & 40 & 140 & 5 \\
\hline 29 & 60 & 2 & 44 & 40 & 136 & 5 \\
\hline 30 & 63 & 2 & 48 & 50 & 132 & 4 \\
\hline 31 & 83 & 3 & 66 & 50 & 126 & 6 \\
\hline 32 & 80 & 3 & 62 & 43 & 130 & 7 \\
\hline 33 & 55 & 2 & 46 & 40 & 120 & 5 \\
\hline
\end{tabular}


TABLE I-continued.

\begin{tabular}{|c|c|c|c|c|c|c|}
\hline \multirow{2}{*}{$\begin{array}{c}\text { DISTANCE } \\
\text { FROM } \\
\text { ORA } \\
\text { SERRATA }\end{array}$} & \multicolumn{2}{|c|}{$\begin{array}{c}\text { TEMPORAL SIDE } \\
\text { (degenerated) }\end{array}$} & \multicolumn{2}{|c|}{$\begin{array}{l}\text { PER CENT. OF } \\
\text { NORMAL }\end{array}$} & \multicolumn{2}{|c|}{$\begin{array}{l}\text { NASAL SIDE } \\
\text { (normal) }\end{array}$} \\
\hline & Rods & Cones & Rods & Cones & Rods & Cones \\
\hline 34 & 60 & 2 & 43 & 34 & 140 & 6 \\
\hline 35 & - & - & - & - & 132 & 7 \\
\hline 36 & - & 一 & - & - & 140 & 6 \\
\hline 37 & - & - & - & - & 140 & 7 \\
\hline 38 & - & -- & - & - & 135 & 6 \\
\hline 39 & - & - & - & - & 138 & 7 \\
\hline 40 & - & - & - & - & 160 & 6 \\
\hline 41 & - & - & - & - & 178 & 6 \\
\hline 42 & - & - & - & - & 192 & 6 \\
\hline 43 & - & - & - & - & 190 & 7 \\
\hline 44 & - & 一 & - & - & 198 & 6 \\
\hline 45 & - & 一 & - & - & 165 & 7 \\
\hline 46 & - & - & - & - & 195 & 7 \\
\hline 47 & - & - & - & - & 178 & 8 \\
\hline 48 & - & - & - & - & 204 & 8 \\
\hline 49 & 75 & 3 & 38 & .37 & 200 & 8 \\
\hline 50 & 150 & 7 & 61 & 100 & 195 & 7 \\
\hline 51 & 155 & 7 & 89 & 88 & 175 & 8 \\
\hline 52 & 203 & 10 & 105 & 143 & 195 & 7 \\
\hline 53 & 158 & 8 & 84 & 100 & 189 & 8 \\
\hline 54 & 165 & 8 & 85 & 80 & 195 & 10 \\
\hline 55 & 170 & 9 & 85 & 113 & 200 & 8 \\
\hline 56 & 185 & 9 & 95 & 90 & 195 & 10 \\
\hline 57 & 195 & 9 & 106 & 100 & 184 & 9 \\
\hline 58 & 180 & 9 & 89 & 113 & 190 & 8 \\
\hline 59 & - 210 & 10 & 112 & 125 & 178 & 8 \\
\hline 60 & 184 & 8 & 78 & 80 & 225 & 10 \\
\hline 61 & 190 & 9 & 79 &. .82 & 240 & 11 \\
\hline 62 & 213 & 10 & 86 & 99 & 248 & 11 \\
\hline 63 & 234 & 11 & 101 & 100 & 230 & 11 \\
\hline 64 & 243 & 11 & 108 & 93 & 224 & 12 \\
\hline 65 & 260 & 12 & 105 & 100 & 248 & 12 \\
\hline
\end{tabular}

N.B.-Distance from the ora serrata is measured in oil immersion fields. One field equals $0.175 \mathrm{~mm}$. Numbers in italics indicate area of degeneration. 
The histological changes produced confirm absolutely those found by Wagenmann. The essential change is a massive degeneration of the retina, starting with the deeper layers and progressing through the retina to the surface. Superficially the degeneration starting with the rods and cones is similar to that found in retinitis pigmentosa. But here the similarity ends. Although the whole picture is unlike that of retinitis pigmentosa, it is true that the appearance of certain areas, particularly in the border regions can be picked out as very like the picture in that condition. A closer examination of the histological details, however, shows their all important differences. There is, for instance, much less gliosis and fibrosis in the present lesion than in retinitis pigmentosa, as, indeed, one might expect in a lesion that is so much more rapid in its progress. Pigment distribution also is entirely different. It remains in the deeper layers of the retina unless there has been complete destruction of all retinal layers, and at no.time has it any relationship to the vessels of the retina.

Bourne, Campbell and Tansley (1938) have described a form of familial degeneration of the retina in rats, the histological features of which are indistinguishable from those of retinitis pigmentosa.

In this condition the rods degenerate first, to be followed only some time later by the cones. The first signs of degeneration in these cells are to be found in the nuclei, a characteristic which does not seem to have been previously noted in retinitis pigmentosa, possibly owing to the lack of eyes in the earlier stages of disease, available for histological examination. If this condition in rats is really a form of retinitis pigmentosa it suggests that these cells die as a consequence of some disturbance of their intracellular metabolism. In the experimental lesion in rabbits the first signs of degeneration are not in the nuclei but in the outer limbs, probably because the nutrition of the cells is disturbed by external influences. The final difference between these two conditions is by far the most important. In retinitis pigmentosa the rods degenerate first, to be followed later by the cones (Stock 1908, Leber 1915, Collins 1919, Verhoeff 1931). In the experimental lesion in rabbits both degenerate equally rapidly.

In conclusion, it may be said that the present findings confirm in all essentials those found by Wagenmann in 1890. A reevaluation of these results shows that they do not support the vascular theory of retinitis pigmentosa. On the contrary, there is much evidence against this theory. To account for some of the features of that disease one must assume some selective difference between the vitality of the rods and that of the cones. 


\section{Summary}

1. Wagenmann's experiments, in which he produced a pigmented degeneration of the retina in rabbits by section of the posterior ciliary arteries have been repeated and confirmed.

2. It has been shown that it is impossible to interfere with the ciliary arteries without injuring the ciliary nerves, but it would seem that one is justified in assuming that the lesions thus produced are the result of a purely vascular disturbance.

3 . It was found impossibie to confirm Wagenmann's statement that section of only a few posterior ciliary arteries was necessary to produce these degenerative retinal lesions. Section of at least two thirds of all the arteries was necessary.

4. The ophthalmoscopic findings following operation were first, an ischaemia of the retina and choroid in the region supplied by the bulk of the vessels cut. This was followed by oedema, and then retinal degeneration in the areas where the circulation had not been restored. The pigment formed conglomerate masses and had no relation to the vessels.

5. Histologically the areas of degeneration showed massive necrosis of all retinal layers starting with the outer layers. At the borders of the regions stages in the process could be seen.

6. The choroid beneath these areas showed for the most part dilated vessels containing blood.

7. The histological appearances taken all together were unlike those of retinitis pigmentosa. Certain areas had a superficial similarity. Detailed examination of the latter showed that there was less gliosis, and a different pigment distribution from what occurs in retinitis pigmentosa. Degeneration of the rods and cones affected their nuclei last of all, and they degenerated equally rapidly.

8. It is concluded that the results of these experiments do not support the vascular theory of the causation of retinitis pigmentosa. On the contrary, evidence was found which is against that theory.

My thanks are due to the Medical Research Council for a grant that made this work possible. I am also greatly indebted to Dr. Katharine Tansley and Dr. R. J. Lythgoe for their invaluable advice and encouragement.

\section{REFERENCES}

1. Bourne, M. C., Campbell, D. A., and Tansley, K.-Hereditary Degeneration of the Rat Retina. Brit. Jl. Ophthal., October, 1938.

2. Capauner. - The Origin of Pigmentation of the Retina. Heidelberg Soc. Rep., p. 45, 1893 .

3. Collins, E. T.-Diseases of the Retina. 1. Abiotrophy of the Retinal Neuro-epithelium or Retinitis Pigmentosa. Trans. Ophthal. Soc. U.K, Vol. XXXIX, p. 165, 1919. 
4. Gonin, M.-Nouvelles Observations de Scotome Annulaire dans la Dégénérescence Pigmentaire de la Retina. Aun. d'Ocul., Vol. CXXVII, p. 90, 1902.

5. Greeves, R. A.-Report of a case of Retinitis Pigmentosa with Pathological Investigation. R.L.O.H. Reps., Vol. XVIII, p. 301, 1912.

6. KR ückmanN, E.-Anatomisches ueber die Pigmentepithelzellen der Retina. Arch. f. Ophthal., Bd. XLVII, pt. 3, p. 644, 1899

7. LeBer, T.-Graefe-Saemisch Handb. d. ges. Augenheilk., Vol. VII, p. 1076, 1915.

8. Menner, E.-Untersuchungen ueber die Retina mit besonderer Berücksichtigung der ausseren Körnerschicht ein Beitrag zur Duplizitätstheorie. Zeits.f. Veigl. Physiol., Bd. VIII, p. 761, 1929.

9. Nettleship, E.-On the Distribution of the Choroidal Arteries as a factor in the localization of certain forms of Choroiditis and Retinitis. R.L.O.H. Reps., Vol. XV, pt. 3, p. 189, 1903.

10. Sтоск W.-Ueber eine bis jetzt noch nicht beschriebene Form der familiar auftretenden Netzhautdegeneration bei gleichzeitiger Verblödung und ueber typische Pigmentdegeneration der Netzhaut. Klin. Monatsbl. $f$. Augenheilk., Bd. XLVI, pt. 1, p. 225, 1908.

11. STuder, T. F.-On Pigmentation of the Retina after Optico Ciliary Neurectomy in Man. Arch. of Ophthal., Vol. XXXV, p. 333, 1906.

12. VerhoEFF, F. H.-Microscopic Observations in a case of Retinitis Pigmentosa. Arch. of Ophthal., Vol. V, p. 392, 1931.

13. WAGENMANN, A.-Experimentelle Untersuchungen ueber den Einfluss der Circulation in den Netzhaut und Aderhautgefässen auf die Ernährung des Auges, insbesondere der Retina, und ueber die Folgen der Sehnervendurchschneidung. Arch. f. Ophthal., Bd. XXXVI, pt. 4, p. 1, 1890.

\section{ANNOTATION}

\section{National Ophthalmic Treatment Board}

The Annual Report of the National Ophthalmic Treatment Board 1937-38 is now to hand. As in previous reports the work of the Board is dealt with under three main headings, viz., Investigation, Education and Administration of the National Eye Service.

With regard to the incidence of pathological conditions in cases of eye defect an analysis has been made last year of a fourth series of 10,000 cases. In each of these four series the returns have been collated by the same competent statistician, and the record cards upon which the returns have been made have remained unchanged. There has been no selection of cases.

The results are arranged in two tables. These should be studied by everyone concerned but it will be of interest if we give a transcript of Table I. "Cases of error of refraction only (1934) 64.09 per cent., (1935) 64.22 per cent., (1936) 63.59 per cent., (1937) 62.54 per cent.

Cases of error of refraction plus one or more other eye conditions (1934) $29 \cdot 15$ per cent., (1935) $27 \cdot 88$ per cent., (1936) $25 \cdot 83$ per cent., (1937) 28.03 per cent.

Cases without error of refraction, but with one or more 'other 